\title{
Caffeine Intake and Dementia: Systematic Review and Meta-Analysis
}

\author{
Catarina Santos ${ }^{\mathrm{a}, \mathrm{b}, *}$, João $\operatorname{Costa}^{\mathrm{c}, \mathrm{d}}$, João Santos ${ }^{\mathrm{c}}$, António Vaz-Carneiro ${ }^{\mathrm{c}}$ and Nuno Lunet ${ }^{\mathrm{a}, \mathrm{b}}$ \\ ${ }^{a}$ Department of Hygiene and Epidemiology, Porto University Medical School, Porto, Portugal \\ ${ }^{\mathrm{b}}$ Institute of Public Health of the University of Porto (ISPUP), Porto, Portugal \\ ${ }^{\mathrm{c}}$ Center for Evidence-Based Medicine, Faculty of Medicine, University of Lisbon, Portugal \\ ${ }^{\mathrm{d}}$ Centro de Investigación Biomédica en Red de Enfermedades Neurodegenerativas (CIBERNED), Spain
}

\begin{abstract}
A recent meta-analysis of 4 studies published up to January 2004 suggests a negative association between coffee consumption and Alzheimer's disease, despite important heterogeneity in methods and results. Several epidemiological studies on this issue have been published since then, warranting an update of the insights on this topic. We conducted a systematic review and meta-analysis of published studies quantifying the relation between caffeine intake and cognitive decline or dementia. Data sources searched included Medline, LILACS, Scopus, Web of Science and reference lists, up to September 2009. Cohort and case-control studies were included. Three independent reviewers selected the studies and extracted the data on to standardized forms. Nine cohort and two case-control studies were included. Quantitative data synthesis of the most precise estimates from each study was accomplished through random effects meta-analysis. Heterogeneity was quantified using the $\mathrm{I}^{2}$ statistic. The outcomes of the studies considered for meta-analysis were Alzheimer's disease in four studies, dementia or cognitive impairment in two studies, and cognitive decline in three studies. The summary relative risk (RR) for the association between caffeine intake and different measures of cognitive impairment/decline was 0.84 [95\% Confidence Interval (95\% CI): 0.72-0.99; $\mathrm{I}^{2}=42.6 \%$ ]. When considering only the cohort studies, the summary RR was 0.93 (95\% CI: $0.83-1.04, \mathrm{I}^{2}=0.0 \%$ ), and 0.77 (95\% CI: $0.63-0.95, \mathrm{I}^{2}=34.7 \%$ ), if the most influential study was excluded. This systematic review and meta-analysis found a trend towards a protective effect of caffeine, but the large methodological heterogeneity across a still limited number of epidemiological studies precludes robust and definite statements on this topic.
\end{abstract}

Keywords: Alzheimer's disease, caffeine, dementia, meta-analysis

\section{INTRODUCTION}

Dementia is a syndrome caused by a range of illnesses, including Alzheimer's disease (AD) (the most prevalent form), vascular, frontotemporal lobe, Lewy body, and other types of dementia [1]. The agestandardized Disability Adjusted Life Years (DALYs) for dementia in 2004 was 260/100,000 in the USA and 350/100,000 in Europe [2]. According to the World

\footnotetext{
* Correspondence to: Catarina Santos, Serviço de Higiene Epidemiologia, Faculdade de Medicina da Universidade do Porto, Alameda Professor Hernâni Monteiro, 4200-319 Porto, Portugal. Tel.: +351 225513652; Fax: +351 225513 653; E-mail: catarinasantos@portugalmail.pt.
}

Health Organization [2], AD and other dementias are the fourth most important cause of DALYs in highincome countries, corresponding to $3.6 \%$ of the total DALYs, a number that is expected to grow up to $5.6 \%$ in 2030 [3]. The growing burden of $\mathrm{AD}$ and other types of dementia have highlighted the importance of research in this field [4], and in recent years there has been a virtual explosion of information concerning the epidemiology, diagnosis, neuropathology, and pathophysiology of dementing disorders.

At present, the efficacy of the pharmacological treatments available is limited and thus, one of the aims of clinical research should be the identification of modifiable risk factors [5] and their interaction with genetic susceptibility markers [6]. Lower education is a recog- 
nized risk factor for dementia [7], and it has been suggested that diabetes mellitus, insulin resistance, high cholesterol, hypertension, reduced exercise, and obesity are also associated with AD [1]. Smoking may also be a risk factor for dementia and AD [8], especially among the APOE $\varepsilon 4$ carriers [6]. The potential effect of diet on the prevention of dementia [9] and cognitive decline further extends this research field, and caffeine intake has been receiving growing attention.

Caffeine is a widely available and consumed substance [10], and it displays affinities for several kinds of receptors present in the synaptic membranes, and also for cytoplasmic phosphodiesterases, enabling the modification of synaptic mechanisms [10]. It acts as a nonselective antagonist of adenosine receptors, and the blockade of $\mathrm{A}_{2 A}$ receptors has recently been demonstrated to limit the synaptotoxic effect of $\mathrm{A} \beta$ [11]. Experimental studies in animal models have also shown that adenosine $\mathrm{A}_{2 A}$ and glutamate mGlu5R receptors are co-located, and that the former play a permissive role in mGlu5R receptor-mediated potentiation of $N$ methyl-D-aspartate (NMDA) effects in the hippocampus [12].

Several epidemiological studies have shown a negative association between coffee drinking and idiopathic Parkinson's disease, another important neurodegenerative condition, particularly in men [13]. The plausible biological mechanisms evoked suggest that caffeine may attenuate the loss of striatal dopamine and dopamine transporter binding sites [14].

A recent meta-analysis [15] of 4 studies published up to January 2004 suggests a negative association between coffee consumption and Alzheimer's disease, despite important heterogeneity in methods and results. Several epidemiological studies on this issue have been published since then, warranting an update of the insights on this topic.

We aimed to review systematically and summarize the published studies, addressing the effect of caffeine in cognitive decline and dementia, and to discuss the methodological heterogeneity of the available evidence.

\section{MATERIAL AND METHODS}

\section{Search strategy}

Potential eligible studies were identified though an electronic search of the databases Medline, LILACS (Latin America and Caribbean), Scopus, and Web of
Science, and by extensive searching using cross references from original articles and reviews. Electronic databases were searched from inception to September 2009. The search used the following terms to identify the risk exposure (coffee OR caffeine) combined with terms to identify the outcomes of interest: dementia OR Alzheimer OR [(Alzheimer* OR vascul* OR cerebrovascular OR cereb*) AND (dement* OR deteriorat* OR insufficien*)] OR [(cognit* OR memory* OR mental*) AND (declin* OR impair* OR los* OR deteriorat*)]. When applicable, we searched all terms as indexed and as free text terms to increase sensitivity. A search filter was developed (Cohort Studies OR Case Control Studies OR Prospective Studies OR Follow-Up Studies OR Cross-Sectional Studies OR Retrospective studies OR Epidemiological OR Incidence OR Risk Factors OR Risk Assessment OR Risk Reduction OR Relative Risk OR Behavior Regression Analysis OR Multivariate Analysis OR Proportional Hazards Models) and applied to the search results in order to retrieve epidemiological studies. There were no language restrictions on searching. We screened titles, keywords, and abstracts of the citations downloaded from the electronic searches and obtained full copies of potentially suitable reports for further assessment. We considered studies published as a full paper or abstract as long as relevant data could be extracted.

\section{Selection criteria}

We included studies with a cohort, case-control and cross-sectional design that addressed the relation between caffeine consumption, through coffee and/or tea intake regardless of assessment of other dietary sources of caffeine, and different forms of dementia, cognitive impairment, or cognitive decline (all diagnostic criteria were considered).

Cross-sectional studies or analyses relying on retrospective assessment of exposure were excluded when cognitively impaired subjects were the informants for estimation of their own caffeine intake. No studies were excluded a priori for weakness of design or data quality. However, to be included in the meta-analysis, studies had to provide or allow the calculation of the relative risk (RR), or the odds ratio (OR) in case-control studies, and the respective variance estimates.

An additional cohort study being published in the current issue of the Journal of Alzheimer's Disease was also considered in this review [16]. 


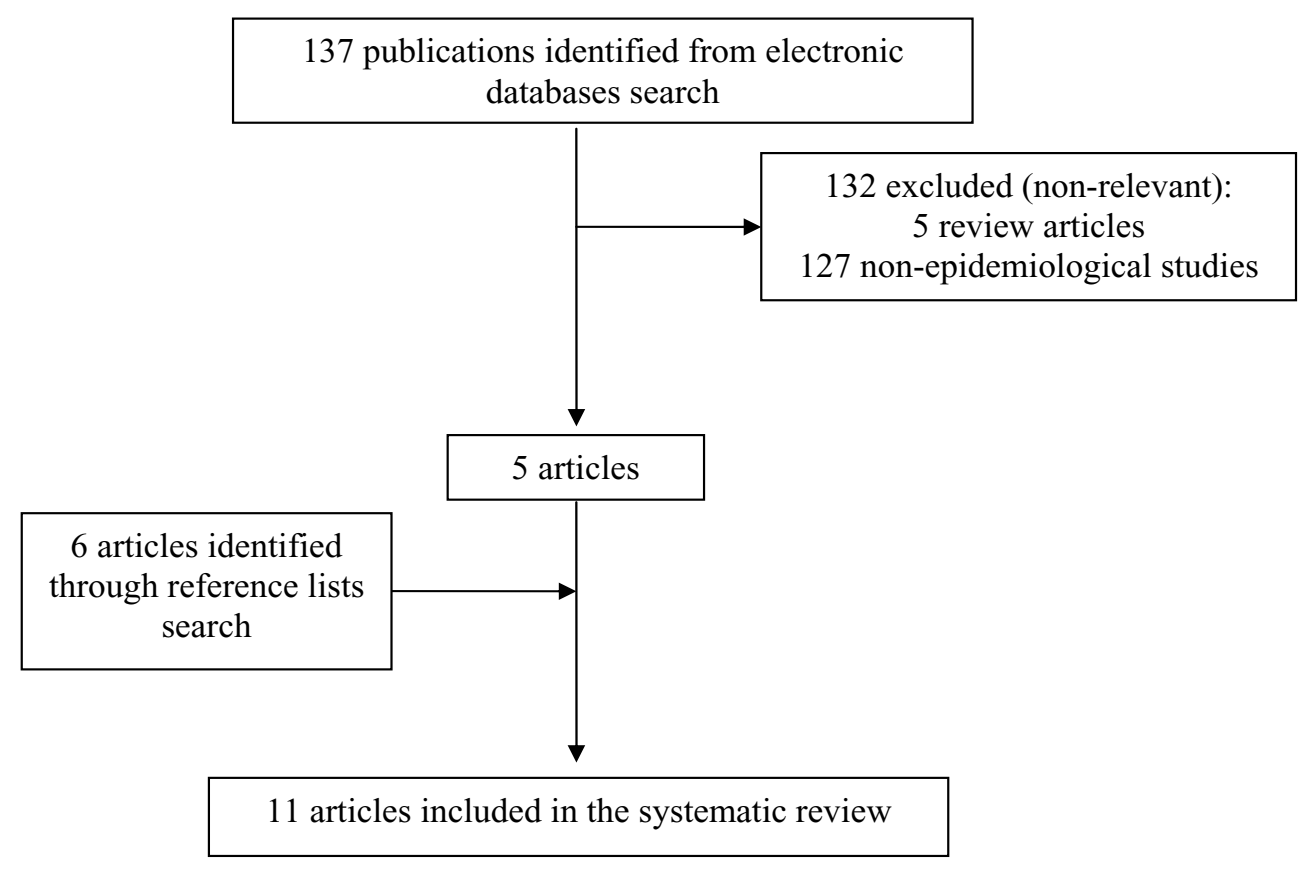

Fig. 1. Systematic review flow-chart.

\section{Data extraction}

The selected articles were reviewed independently by three researchers (JC, JS and CS) and data were extracted using a predefined form. Discrepancies in the evaluation of the articles were resolved by consensus, involving a fourth researcher (NL).

From each study we collected information on: year of publication; country of origin, and population evaluated (general description, number, age, and gender of the participants); type of study (cohort, nested case-control, case-cohort, population- or hospitalbased case-control); exposure assessment (instruments, period of exposure, and informants); outcomes and criteria for outcome definition; control for confounding; data on the relation between caffeine exposure and the outcomes. From cohort studies we also extracted information regarding the length and completeness of follow-up.

In the report by Broe and colleagues [17], one of the comparisons presented had lifelong consumers as the reference category, and we computed the OR using nonconsumers as the reference class, as the distribution of matched pairs across exposure categories was provided.

When a study provided results with different degrees of adjustment for confounders, the estimates adjusted for the largest number of possible confounding vari- ables were selected. Sex-specific results were extracted whenever available.

The authors from the studies included in the present systematic review were not contacted to retrieve additional data.

\section{Data synthesis and meta-analysis}

Each study is summarized in Table 1 and Fig. 2. The results from studies not providing RR estimates are described in the text. Data synthesis is further accomplished through meta-analysis (Fig. 3) and visual inspection of scatter plots representing the log Relative Risk (RR) estimates from each study according to the distribution of methodological characteristics with potential impact on the heterogeneity of results (Fig. 5).

Studies were grouped by the outcome addressed. Dementia and Alzheimer's disease were defined according to the existing clinical criteria (DSM-IV and/or NINCDS-ADRDA). Cognitive decline was considered when studies quantified the difference in score performance using neuropsychological instruments in two distinct occasions, regardless of the cutoff values. An abnormal score in at least one of the tests, at any time, was defined as cognitive impairment.

The forest plot corresponding to Figure 2 represents the RR estimates provided in each study for the association between caffeine intake and dementia. Sev- 


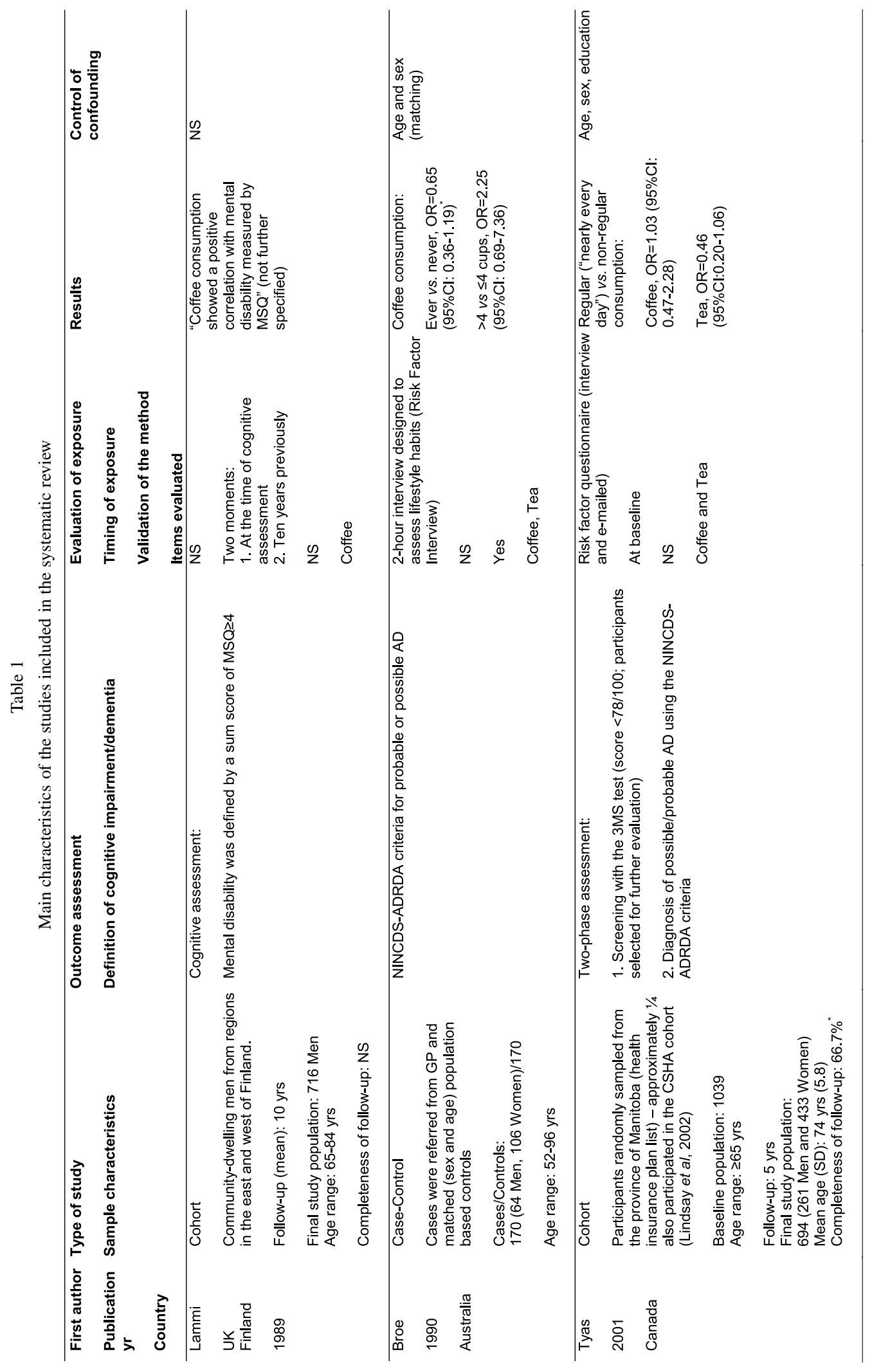




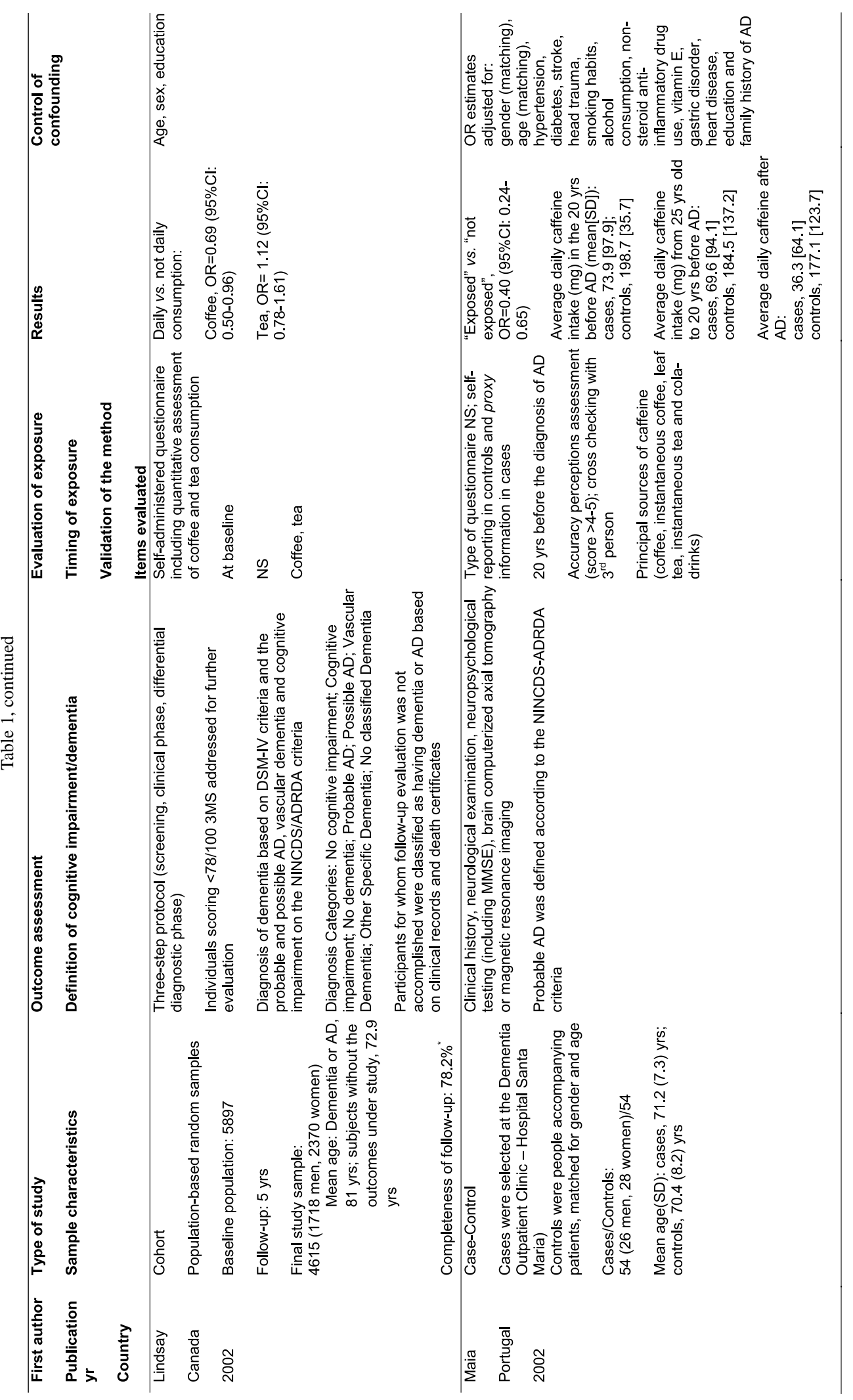




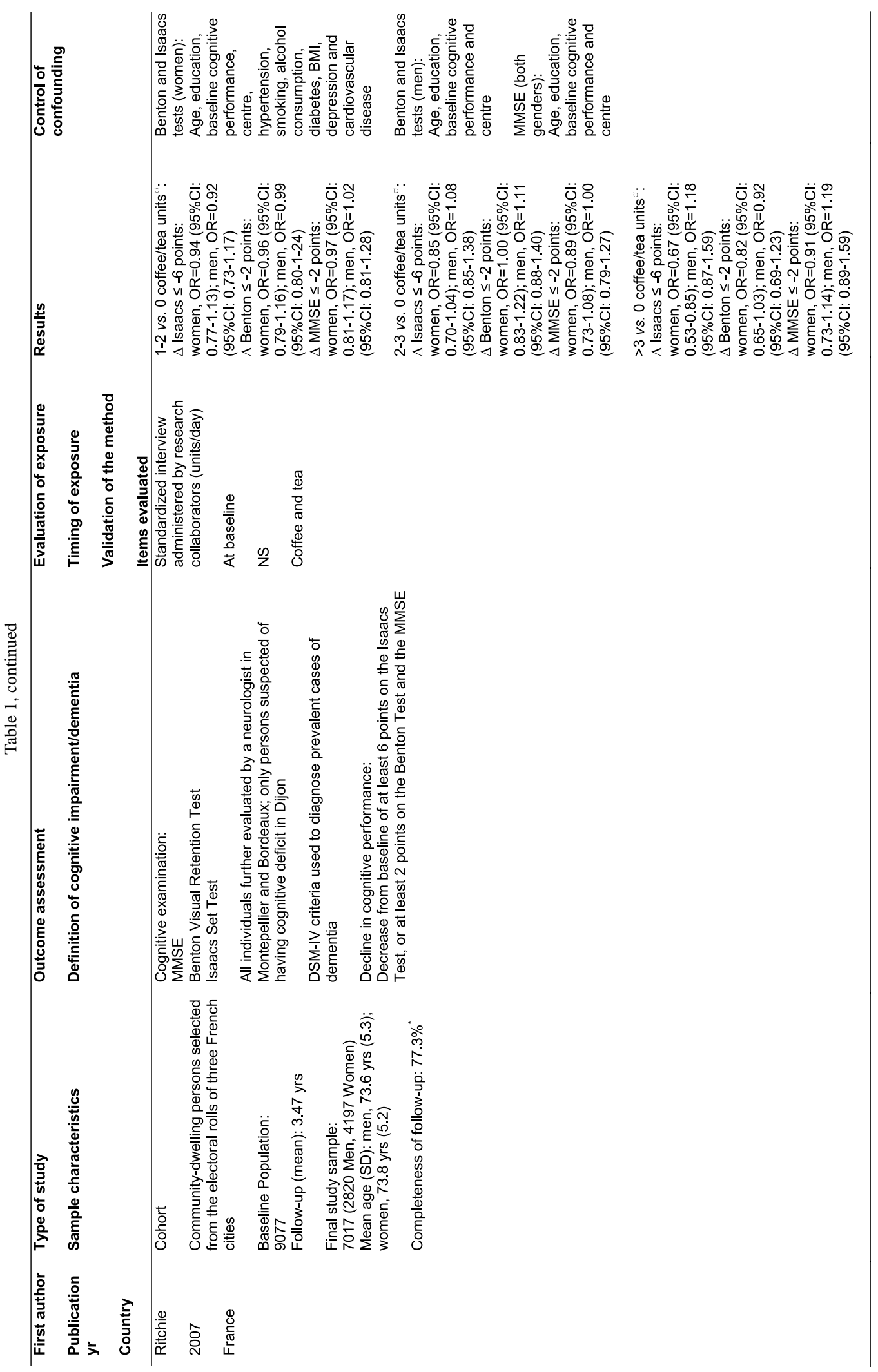




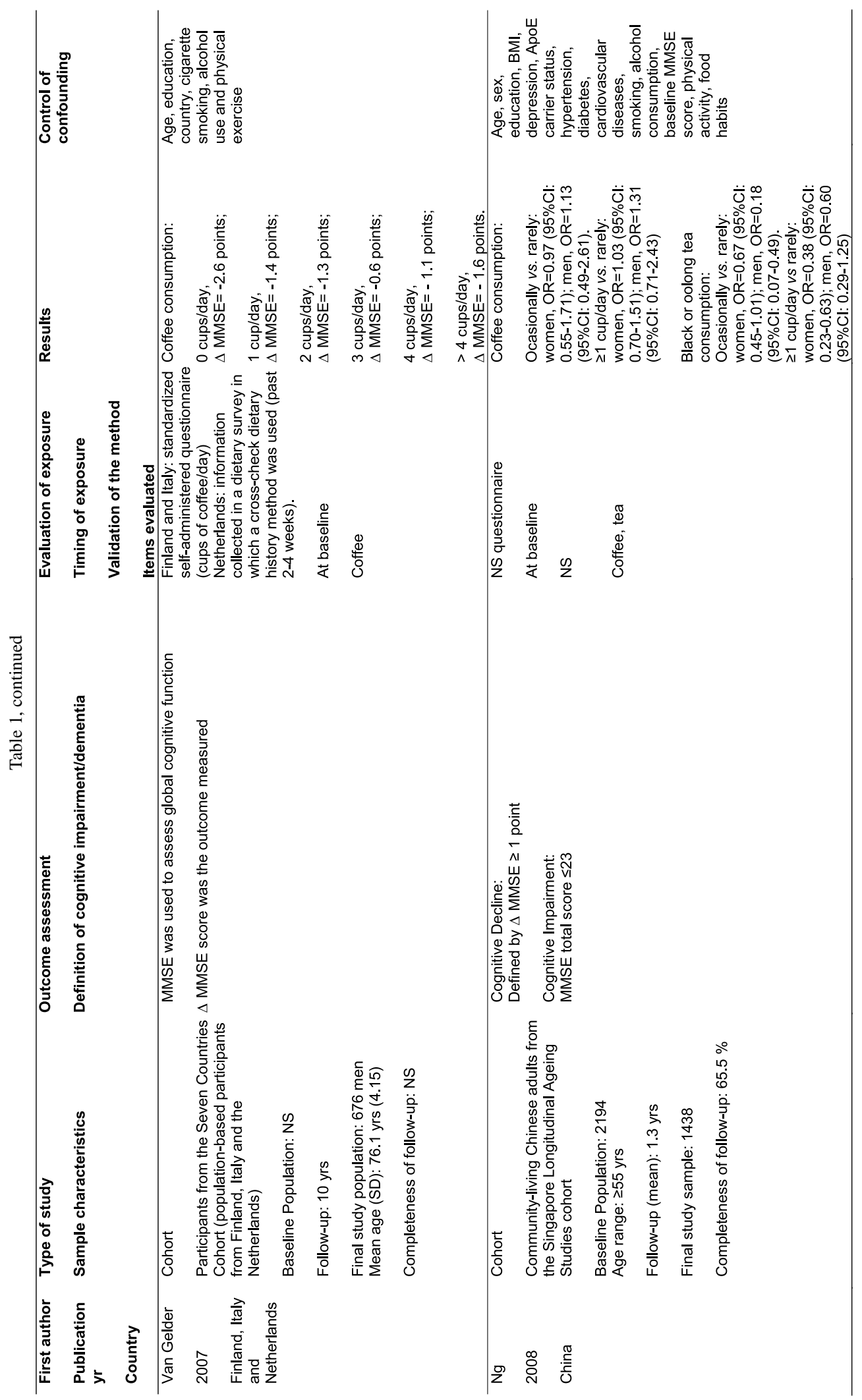




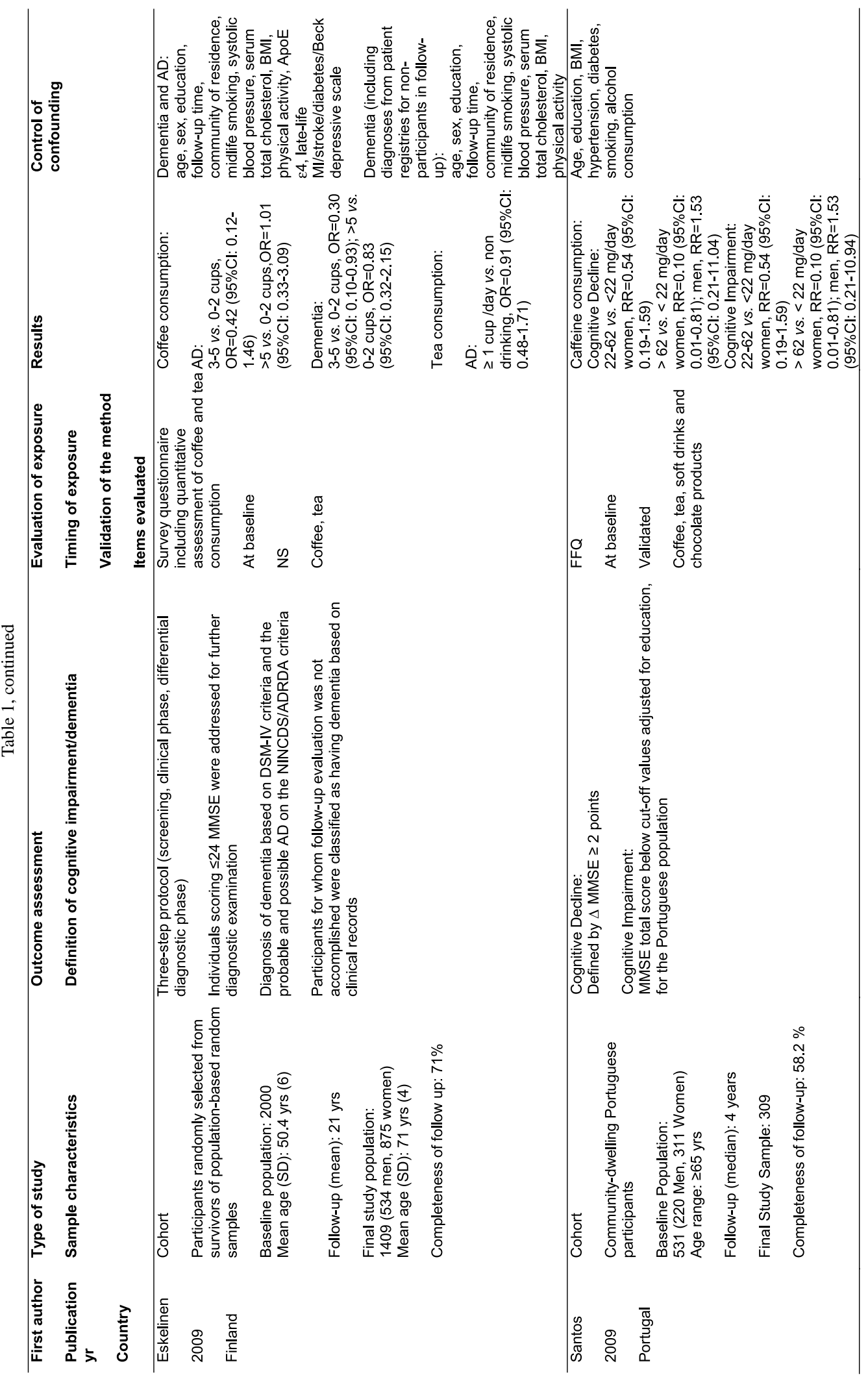




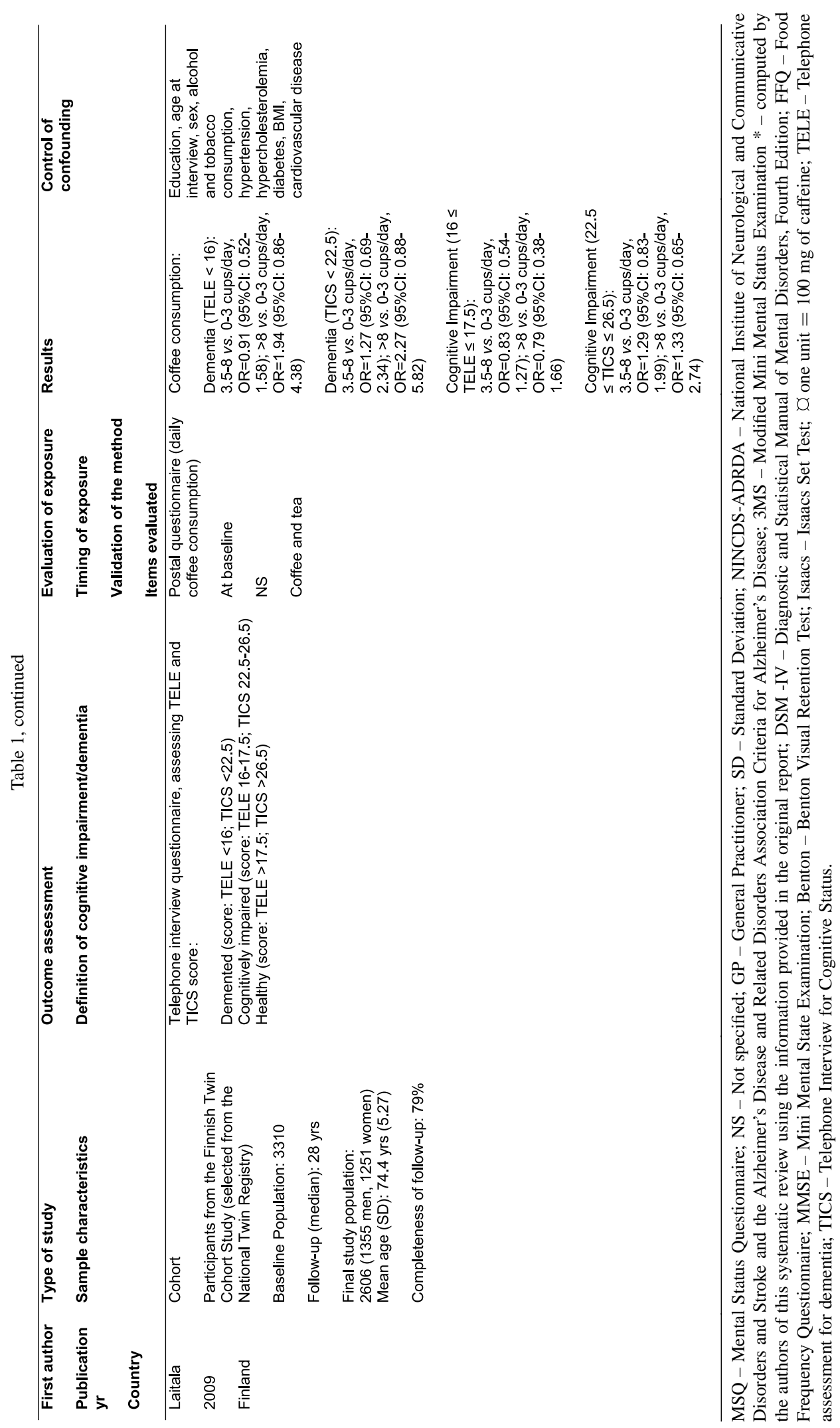




\begin{tabular}{|c|c|c|}
\hline $\begin{array}{l}\text { Study } \\
10\end{array}$ & Exposure & Levels of exposure \\
\hline $\begin{array}{l}\text { Alzheimer's disease } \\
\text { Broe, } 1990 \\
\text { Broe, 1990 } \\
\text { Tyas .2001 } \\
\text { Lindsay, 2002 } \\
\text { Maia, 2002 } \\
\text { Eskelinen, 2009 } \\
\text { Eskelinen, 2009 }\end{array}$ & $\begin{array}{l}c \\
c \\
c \\
c \\
c B \\
c B \\
c \\
c\end{array}$ & 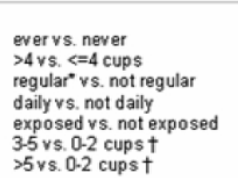 \\
\hline $\begin{array}{l}\text { Dementia } \\
\text { Eskelinen, 2009 } \\
\text { Eskelinen, 2009 } \\
\text { Laitala. 2009a } \\
\text { Laintala,2009a } \\
\text { Laitala. 20096 } \\
\text { Laitala, 2009b }\end{array}$ & $\begin{array}{l}c \\
c \\
c \\
c \\
c \\
c\end{array}$ & $\begin{array}{l}3-5 \text { vs. } 0.2 \text { cups } \dagger \\
>5 \times s .0-2 \text { cups } \dagger \\
3.5-8 \text { vs. } 0.3 \text { cups } \dagger \\
>8 \text { vs. } 0.3 \text { cups } ~ \\
3.5-8 \text { vs. } 0.3 \text { cups } \dagger \\
>8 \text { vs. } 0.3 \text { cups } \dagger\end{array}$ \\
\hline $\begin{array}{l}\text { Cognitive impaiment } \\
\text { Laitala, 2009c } \\
\text { Latitala, 2009c } \\
\text { Laitala, 2009d } \\
\text { Latiala, 2009d } \\
\text { Santos, 2009e (F) } \\
\text { Santos. 2009e (F) } \\
\text { Santos, 2009e (F) } \\
\text { Santos.2009e (M) } \\
\text { Santos, 2009e (M) }\end{array}$ & $\begin{array}{l}C \\
C \\
C \\
C \\
C B+C h o c . \\
C B+C h o c \\
C B+C h o c \\
C B+C h o c . \\
C B+C h o c .\end{array}$ & 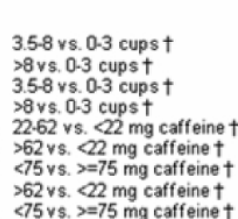 \\
\hline 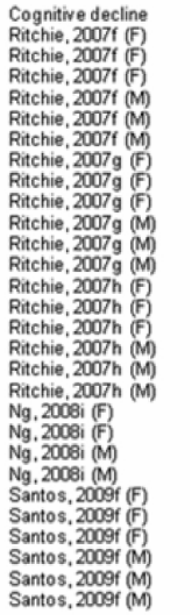 & $\begin{array}{l}C+T \\
C+T \\
C+T \\
C+T \\
C+T \\
C+T \\
C+T \\
C+T \\
C+T \\
C+T \\
C+T \\
C+T \\
C+T \\
C+T \\
C+T \\
C+T \\
C+T \\
C+T \\
C \\
C \\
C \\
C \\
C B+C h o c \\
C B+C h o c \\
C B+C h o c . \\
C B+C h o c \\
C B+C h o c \\
C B+C h o c .\end{array}$ & 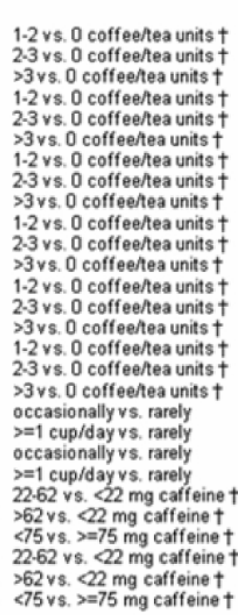 \\
\hline & & \\
\hline
\end{tabular}

Fig. 2. Relative Risk estimates for the association between caffeine and different forms of dementia/cognitive decline, according to sources of caffeine intake and levels of exposure. *regular consumption stands for "nearly every day"; $\dagger$ daily consumption a - TELE $<16$; b - TICS $<$ $22.5 ; \mathrm{c}-16 \leqslant$ TELE $\leqslant 17.5 ; \mathrm{d}-22.5 \leqslant$ TICS $\leqslant 26.5 ; \mathrm{e}-$ MMSE; $\mathrm{f}-\Delta$ MMSE $\leqslant-2 ; \mathrm{g}-\Delta$ Benton $\leqslant-2 ; \mathrm{h}-\Delta$ Isaacs $\leqslant-6 ; \mathrm{i}-\Delta$ MMSE $\leqslant-1 ; \mathrm{M}-$ Male; F - Female; C - coffee; $\mathrm{T}$ - tea; C+T - coffee and tea; CB - caffeinated beverages; CB+Choc. - caffeinated beverages and chocolate.

eral estimates from the same study may be provided, referring to different exposures (e.g., coffee consumption or caffeine intake estimated through a food frequency questionnaire) and levels of exposure, different outcomes (e.g., dementia and cognitive impairment), and different criteria for definition of the same outcome (e.g., variation in Mini Mental State Examination (MMSE) or in Benton Visual Retention Test scores to define cognitive decline).

Quantitative data synthesis was accomplished thro- ugh random effects meta-analysis (DerSimonian and Laird method), conducted with STATA ${ }^{\circledR}$, version 9.2. Relative Risks (cumulative incidence ratios or incidence density ratios), and ORs were treated the same and are referred to as RR [18]. Summary estimates for exposure to caffeine were computed considering the individual RR estimates corresponding to coffee, coffee and tea, or overall caffeine intake, as available from each article, under the assumption that coffee is the main contributor for caffeine intake $[19,20]$. 


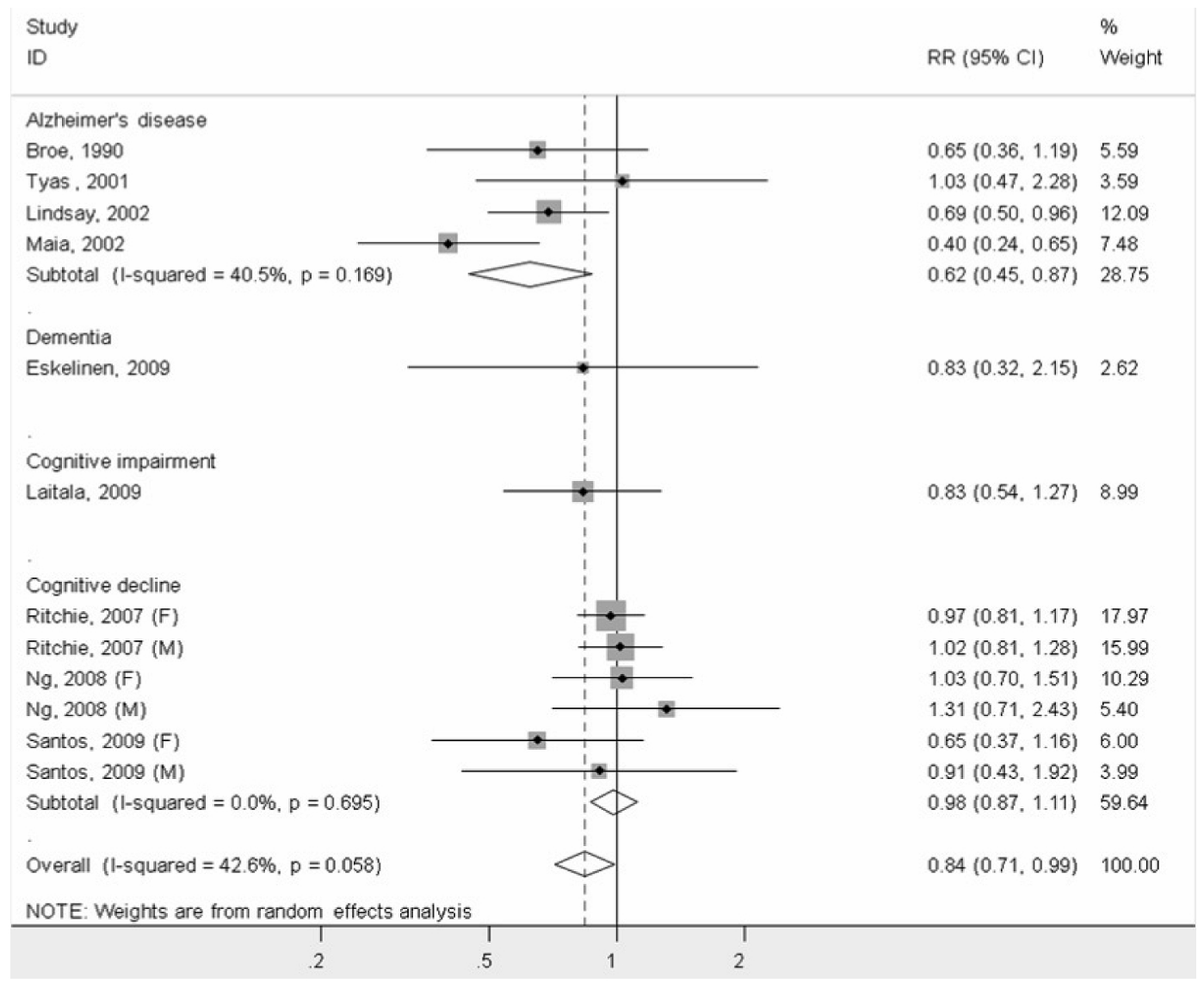

Fig. 3. Meta-analysis for the association between caffeine and different forms of dementia/cognitive decline, including the most precise RR estimates from each individual study. ID - Identification; RR - Relative Risk; M - Male; F - Female.

Since more than one RR estimate were available from several studies and the small number of independent investigations precluded meaningful subgroup or trend estimation analyses, only the most precise measures of association were used from each report (except for sexspecific estimates, which were considered separately as if obtained from different studies). These criteria were applied to the selection of a single estimate per study when RR estimates were provided for different categories of exposure. The reports by Eskelinen et al. [21], Laitala et al. [20], and Santos et al. [16] provided RR estimates for different outcomes, and only the results for the outcome with the most precise estimates were considered. Laitala et al. [20] defined the same outcome using different criteria, and only the criterion with the most precise estimates was considered. Ritchie et al. [22] addressed the effect of caffeine on cognitive decline, relying on three different methods for assessment of cognitive performance, and the estimates corresponding to variation in the MMSE score were selected to allow a more meaningful comparison with the other studies assessing the risk of cognitive decline [16,19].

Heterogeneity was quantified using the $I^{2}$ statistic [23]. Sensitivity analyses were conducted excluding highly influential studies or those not providing RR estimates adjusted for potentially important confounding factors in addition to age and sex. The report by Tyas et al. [24] refers to a subsample of the study published by Lindsay et al. [25], and was also excluded in sensitivity analysis.

Publication and publication-related biases were examined through visual inspection of the funnel plot (Fig. 4). The Begg adjusted rank correlation test [26], and the Egger's regression asymmetry test [27] were used for further assessment of these biases through hypothesis testing.

Figure 5 includes scatter plots aiming to further explore the reasons for heterogeneity of results within and across cohort studies. Only results from studies pro- 


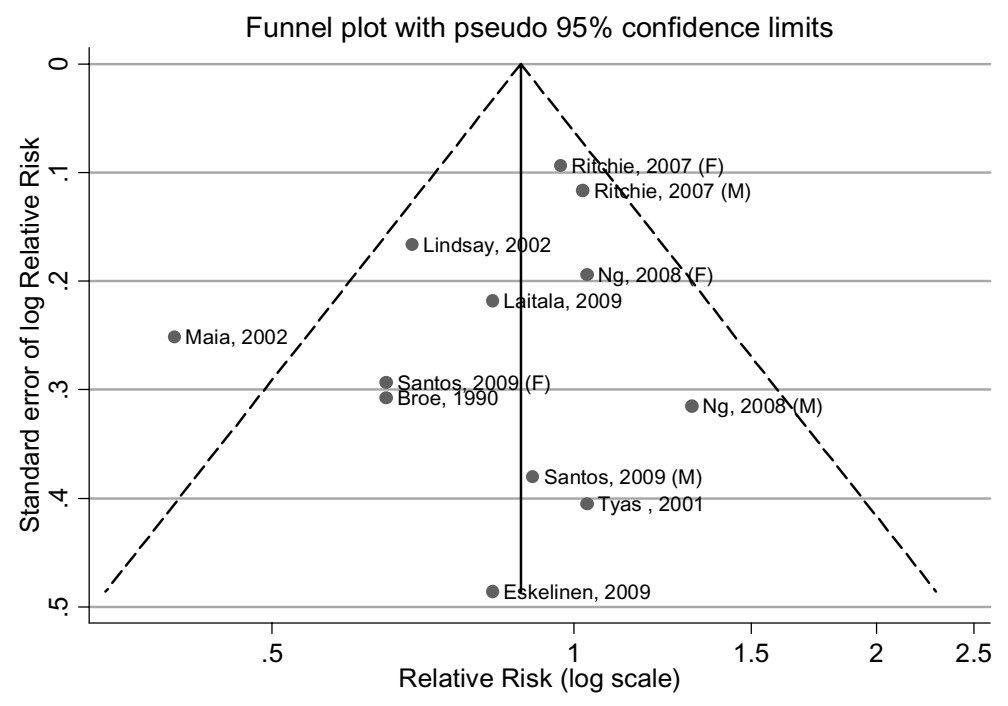

Fig. 4. Meta-analysis funnel plot. M-Male; F-Female.

viding RR estimates for at least two categories of exposure compared with the referent were plotted. In each study, when more than one criterion was used to define the same outcome, only the results corresponding to the criterion yielding the more precise estimates were selected. All the RR estimates corresponding to each outcome addressed in the eligible studies were represented. In Fig. 5a the log RR is represented across levels of caffeine intake. The exposures considered for RR estimates were assumed to correspond to the midpoint of the index category range subtracted by the midpoint of the reference category range. For this purpose, we assumed that the open-ended upper category had the amplitude of the preceding stratum.

Figure 5 ( $b$ to d) addresses the potential for selection and information bias in each study, using the participants' age at baseline, the duration of follow-up and its completeness as surrogate markers for the latter effects. The pattern of association between these methodological characteristics and the RR estimates from each study may contribute to understand the heterogeneity between studies.

\section{RESULTS}

Eleven studies fulfilled the inclusion criteria for systematic review [16,17,19-22,24,25,28-30]. The main characteristics of the studies and results on the relation between caffeine intake and cognitive impairment are summarized in Table 1 and Fig. 2.
The publication year ranged from 1989 to 2009. The studies were conducted in Europe (three in Finland [20, 29,30], two in Portugal [16,28], one in France [22], one multicentric study conducted in Italian, Finish and Dutch populations [21]); one in Australia [17]; two in Canada [24,25]; and one in China [19]. Two were casecontrol [17,28], and nine were cohort studies [16,19$22,24,25,29,30]$. The age of the youngest participant at the time of baseline evaluation ranged from 37 to 68 years. The results were stratified according to gender in three of the studies $[16,19,22]$, and one was conducted on a male cohort [30].

Different sources of caffeine were accounted for in the reports reviewed. Most studies evaluated coffee and tea intake, assessing their effects separately $[17,19$, $24,25]$, or considering the consumption of both beverages [22]. Two studies extended exposure assessment to all caffeinated beverages $[16,28]$ and products containing chocolate [16]. Van Gelder et al. and Laitala et al. evaluated only coffee consumption [20,30]. Different categories of exposure were considered, ranging from less than one to 8 units, equivalent to coffee cups/day. Also, the reference categories included different proportions of non-caffeine consumers and consumers of different amounts of caffeine (Table 1).

In one study, the outcome was measured as a continuous variable according to the scores obtained in several neuropsychological tests, and a correlation coefficient was the only measure of association reported [29]. Van Gelder and colleagues presented results on the decline in cognitive performance (variation in MMSE scores as a quantitative variable) according to coffee intake [30]. 
a
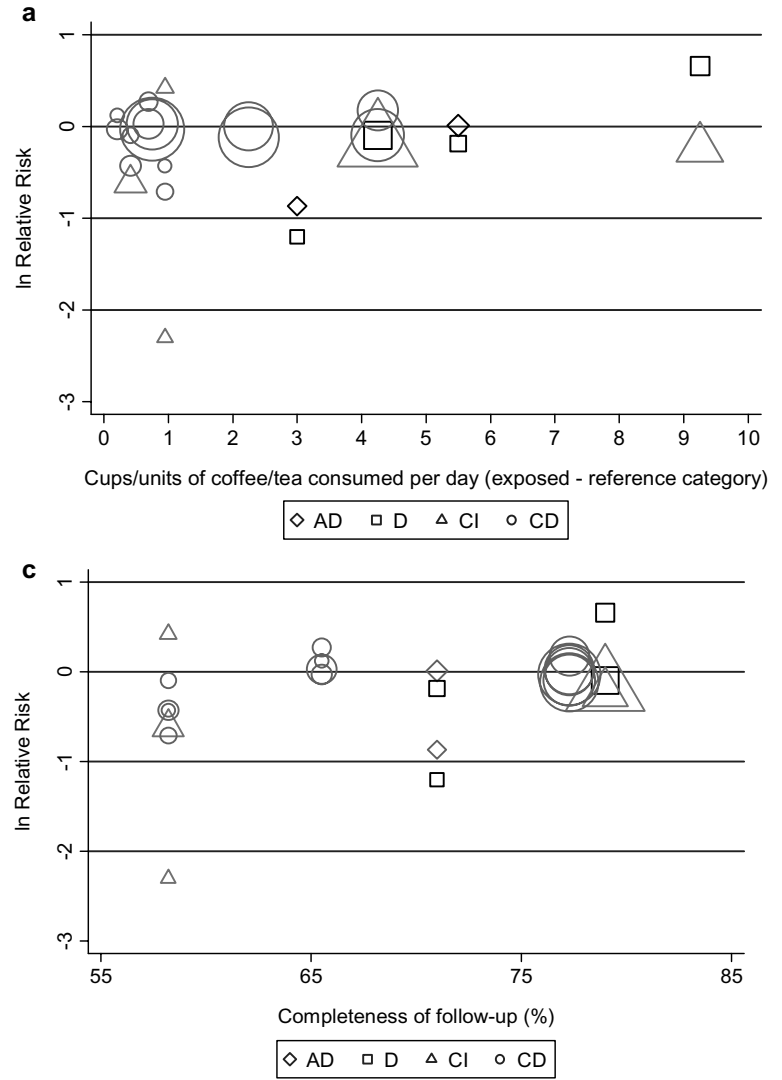

b

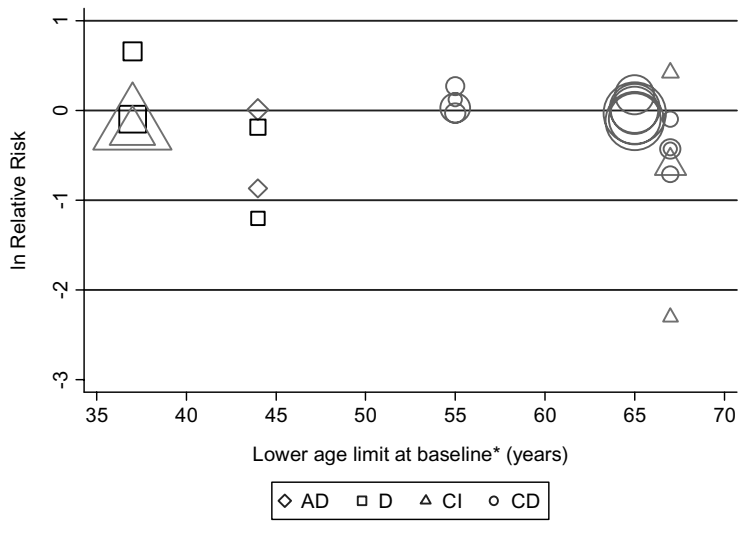

d

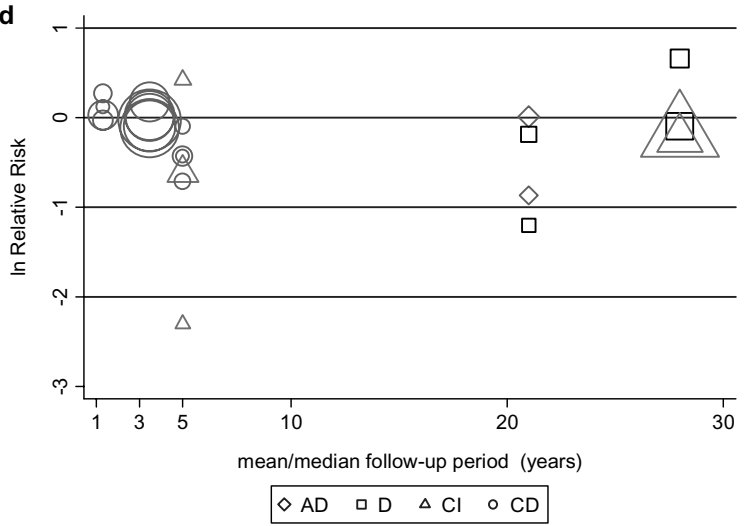

Fig. 5. Relation between caffeine intake, participants' age at baseline, completeness and duration of follow-up and log Relative Risk estimates for the relation between caffeine intake (including only the studies presenting RR estimates for more than one category of exposure) and different measures of cognitive performance*. AD - Alzheimer's disease; D - Dementia; CI - Cognitive impairment; CD - Cognitive decline * the areas of the symbols are proportional to the precision of the estimates, reflecting their relative weight when summary estimates are computed.

RR estimates were computed in nine studies $[16,17$, 19-22,24,25,28] (Fig. 2). Five had Alzheimer's disease as the outcome $[17,21,24,25,28]$, defined by the NINCDS/ADRDA criteria. Of these, only one [21] presented more than one RR estimate to different types of caffeine-containing beverages for the same reference category. Maia and coworkers published a case-control study in which exposure was assessed twenty-years before outcome definition [28]; the work by Broe et al. was also a case-control [17], but did not specify the period to which exposure assessment referred, and the remaining three studies refer to cohort designs $[21,24$, 25]. The risk of dementia (as defined by the authors) or cognitive impairment was assessed in 3 studies. Laitala and collaborators defined the outcomes according to the scores obtained on two sets of cognitive tests designed to be applied by telephone interview [20]. Two other studies used the DSM-IV clinical criteria [21,22].

The MMSE was used in two longitudinal studies designed to assess cognitive decline and impairment over a 5 and 1.5-year period, in Portuguese [16] and Chinese [19] populations, respectively. Ritchie et al. had used the MMSE, as well as other complementary neuropsychological tests, to define decline in cognitive performance [22].

The summary RR for the association between caffeine intake and different measures of cognitive impairment/decline was 0.84 (95\% Confidence Interval: $0.72-0.99)$, with moderate heterogeneity ( $\left.\mathrm{I}^{2}=42.6 \%\right)$. The visual inspection of the funnel plot (Fig. 4) shows no evidence of publication bias, as the results from individual studies scatter around the overall summary RR estimate depicting a funnel-like shape with no meaningful asymmetry. The Egger's regression asymmetry test $(p=0.277)$ and the Begg adjusted rank correlation test $(p=0.784)$ provide further support to the hypothesis of no publication bias.

The two case-control studies provided the strongest negative associations $[17,28]$, corresponding to a summary RR of 0.49 (95\% CI: $0.308-0.791 ; \mathrm{I}^{2}=33.0 \%$ ). 
When considering only the nine cohort studies the summary RR was 0.93 (95\% CI: 0.83-1.04) and results were homogeneous $\left(\mathrm{I}^{2}=0.0 \%\right)$. Among the cohort designs, the study by Ritchie et al. [22] is highly influential, with a weight of $60 \%$ in the overall RR estimate. When the more influential study is excluded, summary RR for all studies was 0.77 (95\% CI: $0.63-0.95, \mathrm{I}^{2}=$ $34.7 \%$ ), and the summary RR for cohort studies was 0.85 (95\% CI: $0.71-1.01, \mathrm{I}^{2}=0.0 \%$ ) The sample evaluated by Tyas et al. [24] partially overlapped with the larger one studied by Lindsay and colleagues [25], but had a small weight in the overall estimates and its exclusion did not change the overall conclusions meaningfully.

The summary RR was 0.83 (95\% CI: $0.32-2.15, \mathrm{I}^{2}=$ $40.5 \%$ ) for Alzheimer's disease, although it combines estimates from 2 case-control and 2 cohort studies, and 0.98 (95\% CI: $0.87-1.11, \mathrm{I}^{2}=40.5 \%$ ) for cognitive decline, but results are driven predominantly by a single large study [22].

The studies by Lammi et al. [29] and van Gelder et al. [30] did not provide RR estimates for the association between caffeine and dementia. The latter suggests a protective effect, although only a correlation coefficient was used to quantify the association, and the former a protective effect with a J-shaped pattern.

The studies considered for meta-analysis provided estimates adjusted for different potential confounding factors and for a varying number of variables, but there was no clear pattern regarding the degree of confounding control and the RR estimates. The summary RR was 0.80 (95\% CI: $\left.0.59-1.08, \mathrm{I}^{2}=51.6 \%\right)$ when considering only 5 studies (7 RR estimates), providing RRs adjusted for both smoking and hypertension, and 0.90 (95\% CI: 0.76-1.06) for the remaining 4 studies (5 RR estimates).

Regarding the relation between levels of exposure to caffeine and the RR estimates (Fig. 5a), results were more heterogeneous for lower intakes, albeit the preponderant role of the study published by Ritchie and colleagues [22] in this particular analysis, but were also more likely to be inversely associated with the outcomes.

Survival bias is likely to occur in non-inception cohorts, and is expectedly stronger in older cohorts [31]. The extent to which a complete follow-up is not achieved also reflects selection bias, in addition to the latter. Changes in caffeine consumption habits with time and with the development of cognitive impairment may contribute to information bias, especially when follow-up periods are longer. Cohort studies including younger participants, having longer or more complete follow-ups, yielded more homogeneous results and the putative protective role of caffeine was more evident in those enrolling older individuals, when follow-up was more complete or shorter (Figs 5b, 5c and 5d). However, no linear relation or other consistent pattern was observed between log RR estimates and age of the cohort participants, follow-up duration or completeness of follow-up.

\section{DISCUSSION}

This systematic review and meta-analysis updates a previous quantitative synthesis based in a small number of studies and provides a summary of the best available evidence on this topic. The large methodological heterogeneity across a still limited number of reports is probably the most remarkable observation in our study, which precludes robust and definite statements on a possible negative association between caffeine intake and dementia.

The conclusions reached by systematic reviews and meta-analyses depend, among other factors, on the comprehensiveness of the search strategy and on the criteria for study inclusion and selection of data for quantitative synthesis. These issues have implications in the validity of our findings and deserve further discussion.

The number of studies available for review was small, namely when compared to the 43 reported included in a recent meta-analysis on smoking and Alzheimer's disease [32]. However, studies on the etiologic role of caffeine intake are less frequent than those focusing on the effects of tobacco, as shown in two meta-analyses addressing the association between coffee drinking, cigarette smoking and Parkinson's disease, with 13 and 48 individual studies, respectively [33]. Furthermore, there was no evidence of publication bias.

Two studies [29,30] did not provide RR estimates for the association between caffeine and dementia, both suggesting a protective effect, but no changes in the conclusions of the present review and meta-analysis would be expected if these studies could be included, given the large heterogeneity observed across the investigations. Two reports providing only a cross-sectional assessment of the association between caffeine intake and dementia [34,35] were not included in the review since the RR estimates were likely to be biased, because in participants cognitively impaired the exposure 
information was obtained by self-report. One of these studies concluded that caffeine intake was associated with a better cognitive performance in tests evaluating reaction time, incidental verbal memory and visuospatial reasoning [35]. The study by Johnson-Kozlow et al. suggested a relation between higher current caffeine consumption and a better performance in two cognitive tests (Short Term Recall and Blessed Items) in women [34].

The number of studies on this topic was small and heterogeneous regarding the methodological options. Four different outcomes were investigated in eleven reports (Alzheimer's disease, dementia, cognitive impairment, and cognitive decline), and with the exception of Alzheimer's disease, the instruments and criteria for outcome definition in each report were also heterogeneous. The food sources and chosen categories of exposure also differed widely across studies. Under these circumstances, and taking into account that the same study frequently addresses more than one outcome and presents different definitions of exposure, the criteria used for selection of a RR single estimate from each study is an important determinant of the validity of our conclusions. To select independent observations to be combined in meta-analysis we opted for the more precise estimates from each study, regardless of the corresponding sources and levels of exposure and outcomes assessed. The precision of the individual RR estimates is not dependent on the direction of the association, and with this criterion the selection of the exposures corresponding to the largest number of participants is the most likely. However, if the categories of exposure in each individual study are defined to include a similar number of participants per group, this criterion leads to the selection of the estimates reflecting the weakest associations, which may have contributed to a slight underestimation of the summary RR. On the other hand, the precision of the summary estimates is reduced by considering only part of the overall sample from each study in the meta-analysis. Sensitivity analysis extends the assessment of the robustness of the summary estimates across different inclusion criteria, as well as the discussion of the methodological heterogeneity.

Two case-control studies assessed exposure through surrogate informants, and were therefore eligible for our review; however, misclassification of exposure as well as information bias weaken this methodological approach, especially when a long-term recall of exposure is required. Furthermore, in the case-control study conducted by Broe and collaborators [17], the recall period was not provided and only the potential confound- ing effects of age and gender were accounted for, which precludes a sound discussion of the extent to which recall bias and uncontrolled confounding could have influenced validity of the OR estimates. The exclusion of the case-control studies in sensitivity analysis allowed a meta-analysis of homogeneous results.

Even though Tyas et al. [24] and Lindsay et al. [25] partly share their cohorts of participants, there is a stronger protective effect described for tea in the first case, in a predominantly rural setting, whereas in the second case coffee is the substance associated with a lesser cognitive decline. This may be related to other habits associated with the predominant caffeine intake source; in the study by Lindsay and coworkers [25], the population was essentially urban and this difference may partly account for the results. Nevertheless, the wide categories of exposure used in analysis (daily regular consumption vs. irregular consumption) precluded a finer assessment of the relation between caffeine intake and Alzheimer's disease. A Chinese cohort study evaluating coffee and tea separately and adjusting mutually for these two sources of caffeine showed that total tea intake was significantly associated with a lower prevalence of cognitive impairment, although no protective effect was observed for coffee consumption [19]. In this population, coffee intake was the most commonly consumed caffeine-containing beverage, despite the high proportion of drinkers of different types of tea. The results could be due to the fact that other components rather than caffeine may also exert a role on cognitive decline, but in addition to this Chinese study [19], only Tyas et al. [24] showed associations in different directions for coffee and tea.

Among cohort investigations the summary RR estimate is driven predominantly by the study conducted by Ritchie and coworkers [22], which showed no significant association between decline in MMSE score and caffeine intake. However, a protective effect of caffeine was observed in women, both for verbal and visuospatial memory performances ( $>3$ units of caffeine/day vs. $<1$ unit of caffeine/day: $\mathrm{OR}=0.67 ; 95 \% \mathrm{CI}, 0.53-$ 0.85 , for verbal memory; $\mathrm{OR}=0.82 ; 95 \% \mathrm{CI}, 0.65-$ 1.03 , for visuospatial memory). If these estimates had been selected for our meta-analysis a stronger protective effect would had been achieved. The remaining cohort studies have similar weights in meta-analysis and the exclusion of the highly influential study by Ritchie et al.- yields a stronger risk reduction associated with caffeine intake.

The most recently published cohort study, conducted by Laitala et al. [20], relied on two validated neu- 
ropsychological tests [Telephone Interview for Cognitive Status (TICS) and Telephone Assessment for Dementia (TELE)] to classify participants in relation to dementia or cognitive impairment, but none of the widely adopted clinical criteria were used, and no significant protective effect of caffeine was observed. However, the RR estimate selected for meta-analysis according to previously established criteria was one of the lowest. If other estimates had been selected, the negative association suggested by the summary RR estimate would have been slightly weaker. The studies by Eskelinen et al. [21] and Santos et al. [16] provide RR estimates for different outcomes, but no substantial changes in the summary estimate would have been observed if other individual RR estimates had been selected from each study, except if the levels of exposure considered were different. The differences in the relation between caffeine intake and cognitive function observed in these studies, according to the levels of exposure, depict one of the sources of heterogeneity across cohort studies.

The small number of heterogeneous studies precluded a formal trend estimation analysis, but Fig. 5a allows a systematic approach to the discussion of the dose-response relationship. The results from studies providing RR estimates for different levels of exposure suggest a stronger protective effect for lower consumptions, despite the limited number of studies and the large weight of the study conducted by Ritchie and colleagues do not allow stronger inferences on this issue. The cohort study conducted by van Gelder et al. was not included in meta-analysis because no RR estimates are provided, but reported an inverse J-shaped association between the number of cups of coffee consumed and cognitive decline, with the least decline for three cups a day [30]. The case-control study by Broe et al. [17] provided RR estimates for consumers of more than 4 cups/day vs. consumers of 4 or less cups/day and allowed the computation of estimates for lifetime $v s$. non consumers, showing a protective effect for coffee intake, but a deleterious effect for the consumption of large amounts. A J-shaped relation may therefore be hypothesized, but uncontrolled or residual confounding are also likely explanations for such a pattern.

Cohort designs are less prone to information bias, but also have potential limitations related to survival bias due to the enrollment of non-inception cohorts, and selection bias resulting from incomplete follow-up. Studies less likely to suffer from these biases tended to show weaker negative or even positive associations between caffeine intake and dementia. On the other hand, information bias may also be a concern, especial- ly in studies with longer follow-up, as caffeine intake habits may decrease with time as cognitive impairment occurs, and a protective effect of caffeine was more likely in studies with shorter follow-up.

None of the studies assessed the relation between duration of exposure to caffeine and dementia or cognitive decline, and the timing of exposure evaluation is also a source of heterogeneity across studies. The change in caffeine intake habits over time is difficult to disentangle from the choice of the most appropriate moment to assess exposure, from a biological plausibility point of view. Because there are no definite data as to when caffeine may start exerting its putative role on neurodegeneration, the lag between caffeine exposure and its potential effects on cognitive performance cannot be accurately determined for the time being.

The evaluation of non-inception cohorts is of particular concern in longitudinal studies recruiting older individuals. Because participants suffering from chronic illnesses are more likely to die before being recruited, this will probably lead to an under-representation of individuals at a high risk of cognitive impairment in the cohort. Depending on their caffeine consumption habits and coexisting dementia risk factors, this could lead to biased estimates of risk. Hypertension and smoking are especially important in this discussion; the relation between hypertension and coffee is complex, but it is well recognized that hypertensive patients are less likely to drink coffee due to public perception issues [36]. Because hypertension is a well known risk factor for dementia, the exclusion of such individuals could lead to an underestimation of the protective effect of caffeine in cognitive decline. On the other hand, smokers tend to drink more coffee, are more prone to suffer from chronic illnesses and have a higher mortality rate [32]. Assuming that less fit individuals are more likely to become cognitively impaired, excluding them from study cohorts could lead to an overestimation of the protective effect exerted by caffeine.

The knowledge of caffeine pharmacokinetics is important when discussing its potential neuroprotective role. Caffeine half-life is reduced in smokers [37], which may contribute to a weaker protective effect in tobacco consumers, under the same caffeine exposures. As smoking is associated with coffee consumption, the latter effect is more likely in men, among whom the prevalence of tobacco consumption tends to be higher [38], in accordance with the observation of a stronger protective effect of caffeine in women by some authors $[16,19,22]$. Hormonal replacement therapy (HRT) could also interfere with caffeine metabo- 
lization and constitute another possible explanation for differences between men and post-menopausal women. Studies conducted by Ascherio and coworkers addressing caffeine intake and Parkinson's disease have shown an increasing risk in women on HRT and with higher caffeine intake habits [13]. Regarding cognitive deterioration, Ritchie and collaborators found no interaction between caffeine and HRT [22], but there was no additional data on this issue in the remaining articles reviewed.

Two studies analyzed the potential effect of apolipoprotein E (APOE) gene polymorphisms in the association between caffeine and dementia. The results obtained through stratification according to the APOE $\varepsilon 4$ allele carrier status by Eskelinen et al. suggest a stronger protective effect in APOE $\varepsilon 4$ allele carriers (carriers: moderate consumption $v s$. low consumption: $\mathrm{OR}=0.32,95 \%$ CI $0.11-0.92$; non-carriers: moderate consumption $v s$. low consumption: $\mathrm{OR}=0.44,95 \%$ CI 0.12-1.55) [21]. In the study by $\mathrm{Ng}$ et al., the negative association between tea consumption and cognitive decline in the category defined as "high intake" did not change meaningfully after adjustment for APOE $\varepsilon 4$ allele carrier status $(\mathrm{OR}=0.5795 \%$ CI $0.32-1.03$ after adjustment $v s$. OR $=0.6295 \%$ CI $0.36-1.08$ before adjustment) [19].

Caffeine consumption is significantly associated with a wide range of variables also known as being related to cognitive decline [22]. Vascular risk factors, age, education and depressive symptoms are among the ones generally agreed upon. It is thus relevant to account for these variables as potential confounding factors, which was accomplished in most studies [16,19-21], although to different extents. Uncontrolled or residual confounding and effect modification not accounted for in the majority of studies reviewed may contribute to explain the heterogeneous results, although no formal assessment of these effects is possible due to the small number of highly heterogeneous reports.

Finally, a problem inherent to all dementia research designs is the accuracy of diagnosis. All the studies reviewed rely either on a clinical diagnosis or on neuropsychological test scores. Because the definite diagnosis of dementia requires pathological examination, misclassification is likely to have contributed to biased results [39]. However, the specificity and sensitivity of clinical diagnosis are poorly known and it is recognized that they differ according to the type of dementia (e.g., vascular, Alzheimer's disease) and the criteria used [40, 41]. This reaffirms the importance of internationally consensual criteria for clinical diagnosis of dementia in epidemiological research.

In conclusion, further prospective studies evaluating the association between caffeine consumption and cognitive decline are needed. Addressing the potential bias and confounding sources described above is essential. Setting consensual criteria for the definition of outcome as well as creating defined categories and types of exposure might be useful in conducting meta-analyses, and increase statistical power for the detection of an association between caffeine and cognitive impairment or dementia.

\section{DISCLOSURE STATEMENT}

Authors' disclosures available online (http://www.jalz.com/disclosures/view.php?id=275).

\section{REFERENCES}

[1] Farlow M (2007) Alzheimer's Disease. In Continuum Lifelong Learning in Neurology - Dementia, A. Miller ed. Lippincott Williams \& Wilkins, Philadelphia, pp. 39-63.

[2] World Health Organization, Global Burden of Disease, http://www.who.int/healthinfo/global burden disease/GBD_ report_2004update_full.pdf, Last updated 2009, Accessed on November 04, 2009.

[3] World Health Organization, Global Burden of Disease, http://www.who.int/healthinfo/global_ burden disease/DALY Inc_2030.xls, Last updated 2009, Accessed on November 04, 2009.

[4] Olesen J, Baker MG, Freund T, di Luca M, Mendlewicz J, Ragan I, Westphal M (2006) Consensus document on European brain research. J Neurol Neurosurg Psychiatry 77(Suppl 1), i1-49.

[5] Patterson C, Feightner JW, Garcia A, Hsiung GY, MacKnight C, Sadovnick AD (2008) Diagnosis and treatment of dementia: 1. Risk assessment and primary prevention of Alzheimer disease. CMAJ 178, 548-556.

[6] Kivipelto M, Rovio S, Ngandu T, Kareholt I, Eskelinen M, Winblad B, Hachinski V, Cedazo-Minguez A, Soininen H, Tuomilehto J (2008) Apolipoprotein E epsilon4 magnifies lifestyle risks for dementia: a population-based study. J Cell Mol Med 12, 2762-2771.

[7] Qiu C, De Ronchi D, Fratiglioni L (2007) The epidemiology of dementias: an update. Curr Opin Psychiatry 20, 380-385.

[8] Qiu C, Kivipelto M, von Strauss E (2009) Epidemiology of Alzheimer's disease: occurrence, determinants, and strategies toward intervention. Dialogues Clin Neurosci 11, 111-128.

[9] Gillette Guyonnet S, Abellan Van Kan G, Andrieu S, Barberger Gateau P, Berr C, Bonnefoy M, Dartigues JF, de Groot L, Ferry M, Galan P (2007) IANA task force on nutrition and cognitive decline with aging. $J$ Nutr Health Aging 11, 132-152.

[10] Yoshimura $\mathrm{H}$ (2005) The potential of caffeine for functional modification from cortical synapses to neuron networks in the brain. Curr Neuropharmacol 3, 309-316. 
[11] Canas PM, Porciuncula LO, Cunha GM, Silva CG, Machado NJ, Oliveira JM, Oliveira CR, and Cunha RA (2009) Adenosine A2A receptor blockade prevents synaptotoxicity and memory dysfunction caused by beta-amyloid peptides via p38 mitogen-activated protein kinase pathway. J Neurosci $\mathbf{2 9}$, $14741-14751$

[12] Tebano MT, Martire A, Rebola N, Pepponi R, Domenici MR, Gro MC, Schwarzschild MA, Chen JF, Cunha RA, and Popoli P (2005) Adenosine A2A receptors and metabotropic glutamate 5 receptors are co-localized and functionally interact in the hippocampus: a possible key mechanism in the modulation of N-methyl-D-aspartate effects. J Neurochem 95, 1188-1200.

[13] Ascherio A, Chen H (2003) Caffeinated clues from epidemiology of Parkinson's disease. Neurology 61(11 Suppl 6), S5154.

[14] Chen JF, Xu K, Petzer JP, Staal R, Xu YH, Beilstein M, Sonsalla PK, Castagnoli K, Castagnoli N Jr, Schwarzschild MA (2001) Neuroprotection by caffeine and A(A2) adenosine receptor inactivation in a model of Parkinson's disease. $\mathrm{J} \mathrm{Neu}$ rosci 21, RC143.

[15] Barranco Quintana JL, Allam MF, Serrano Del Castillo A, Fernandez-Crehuet Navajas R (2007) Alzheimer's disease and coffee: a quantitative review. Neurol Res 29, 91-95.

[16] Santos C, Lunet N, Azevedo A, de Mendonça A, Ritchie K, Barros H (2010) Caffeine intake is associated with a lower risk of cognitive decline: A cohort study from portugal. $J$ Alzheimers Dis 20(Supplement), 175-185.

[17] Broe GA, Henderson AS, Creasey H, McCusker E, Korten AE, Jorm AF, Longley W, Anthony JC (1990) A case-control study of Alzheimer's disease in Australia. Neurology 40, 1698-1707.

[18] Rothman KJ, Greenland S, Lash TL (2008) Case-control studies. In Modern Epidemiology, Rothman KJ, Greenland S, Lash TL, eds. Lippincott Williams \& Wilkins, Philadelphia pp. 111127.

[19] Ng TP, Feng L, Niti M, Kua EH, Yap KB (2008) Tea consumption and cognitive impairment and decline in older Chinese adults. Am J Clin Nutr 88, 224-231.

[20] Laitala VS, Kaprio J, Koskenvuo M, Raiha I, Rinne JO, Silventoinen $\mathrm{K}$ (2009) Coffee drinking in middle age is not associated with cognitive performance in old age. Am J Clin Nutr 90, 640-646.

[21] Eskelinen MH, Ngandu T, Tuomilehto J, Soininen H, Kivipelto M (2009) Midlife coffee and tea drinking and the risk of latelife dementia: a population-based CAIDE study. J Alzheimers Dis, 16, 85-91.

[22] Ritchie K, Carriere I, de Mendonça A, Portet F, Dartigues JF, Rouaud O, Barberger-Gateau P, Ancelin ML (2007) The neuroprotective effects of caffeine: a prospective population study (the Three City Study). Neurology 69, 536-545.

[23] Higgins JP, Thompson SG (2002) Quantifying heterogeneity in a meta-analysis. Stat Med 21, 1539-1558.

[24] Tyas SL, Manfreda J, Strain LA, Montgomery PR (2001) Risk factors for Alzheimer's disease: a population-based, longitudinal study in Manitoba, Canada. Int J Epidemiol 30, 590-597.

[25] Lindsay J, Laurin D, Verreault R, Hebert R, Helliwell B, Hill GB, McDowell I (2002) Risk factors for Alzheimer's disease: a prospective analysis from the Canadian Study of Health and Aging. Am J Epidemiol 156, 445-453.

[26] Begg CB, Mazumdar M (1994) Operating characteristics of a rank correlation test for publication bias. Biometrics 50, 10881101.

[27] Egger M, Davey Smith G, Schneider M, Minder C (1997) Bias in meta-analysis detected by a simple, graphical test. $B M J \mathbf{3 1 5}$, 629-634.

[28] Maia L, de Mendonça A (2002) Does caffeine intake protect from Alzheimer's disease? Eur J Neurol 9, 377-382.

[29] Lammi UK, Kivela SL, Nissinen A, Punsar S, Puska P, Karvonen M (1989) Mental disability among elderly men in Finland: prevalence, predictors and correlates. Acta Psychiatr Scand 80, 459-468.

[30] van Gelder BM, Buijsse B, Tijhuis M, Kalmijn S, Giampaoli S, Nissinen A, Kromhout D (2007) Coffee consumption is inversely associated with cognitive decline in elderly European men: the FINE Study. Eur J Clin Nutr 61, 226-232.

[31] Hernan MA, Alonso A, Logroscino G (2008) Cigarette smoking and dementia: potential selection bias in the elderly. Epidemiology 19, 448-450.

[32] Cataldo JK, Prochaska JJ, Glantz SA (2010) Cigarette smoking is a risk factor for Alzheimer's disease: An Analysis controlling for tobacco industry affiliation. J Alzheimer Dis $\mathbf{1 9}$, 465-480.

[33] Hernan MA, Takkouche B, Caamano-Isorna F, Gestal-Otero JJ (2002) A meta-analysis of coffee drinking, cigarette smoking, and the risk of Parkinson's disease. Ann Neurol 52, 276-284.

[34] Johnson-Kozlow M, Kritz-Silverstein D, Barrett-Connor E, Morton D (2002) Coffee consumption and cognitive function among older adults. Am J Epidemiol 156, 842-850.

[35] Jarvis MJ (1993) Does caffeine intake enhance absolute levels of cognitive performance? Psychopharmacology (Berl) 110, 45-52.

[36] Takashima Y, Iwase Y, Yoshida M, Kokaze A, Takagi Y, Taubono Y, Tsugane S, Takahashi T, Iitoi Y, Akabane M (1998) Relationship of food intake and dietary patterns with blood pressure levels among middle-aged Japanese men. J Epidemiol 8, 106-115.

[37] Benowitz NL, Hall SM, Modin G (1989) Persistent increase in caffeine concentrations in people who stop smoking. $B M J$ 298, 1075-1076

[38] Santos AC, Barros H (2004) Smoking patterns in a community sample of Portuguese adults, 1999-2000. Prev Med 38, 114119.

[39] Martin EM, Wilson RS, Penn RD, Fox JH, Clasen RA, Savoy SM (1987) Cortical biopsy results in Alzheimer's disease: correlation with cognitive deficits. Neurology 37, 1201-1204.

[40] Gay BE, Taylor KI, Hohl U, Tolnay M, Staehelin HB (2008) The validity of clinical diagnoses of dementia in a group of consecutively autopsied memory clinic patients. J Nutr Health Aging 12, 132-137.

[41] Gold G, Giannakopoulos P, Montes-Paixao Junior C, Herrmann FR, Mulligan R, Michel JP, Bouras C (1997) Sensitivity and specificity of newly proposed clinical criteria for possible vascular dementia. Neurology 49, 690-694. 